\title{
Modeling the Reliability of High-Voltage Power Transmission Lines Taking into Account the Influence of the Parameters of a Sharply Continental Climate
}

\author{
Elena Gracheva ${ }^{1 *}$, Muhayo Toshkhodzhaeva², Okhunbobo Rahimov², Shakhboz Dadabaev², \\ Dilafruz Mirkhalikova², Svetlana Ilyashenko ${ }^{3}$, Vladimir Frolov ${ }^{4}$
}

${ }^{1}$ Kazan State Power Engineering University, Kazan, Krasnoselskaya Street, 5, 1420066, Russia

${ }^{2}$ Khujand Polytechnic Institute of Tajik Technical University named after Academician M.S. Osimi, Khujand, 735700, Tajikistan

${ }^{3}$ Plekhanov Russian University of Economics, Moscow 117997, Russia

${ }^{4}$ Peter the Great St. Petersburg Polytechnic University, St. Petersburg, 194021, Russia

\begin{abstract}
Natural factors significantly affect the reliability of overhead transmission lines (OHTLs) as the operating conditions change with a change in natural conditions. As such, OHTLs in new natural conditions should be reconstructed optimally so that the number of failures would be less than the standard value. This paper considers the optimal option for $110 \mathrm{kV}$ OHTL reconstruction in a sharply continental climate. Such option should reduce the power supply interruptions without changing the permissible overall dimensions and mechanical properties of the existing OHTLs with minimal economic costs. Mathematical modeling was thus performed using the specially developed Matlab/Simulink software, and the most common types of wires for OHTLs were considered. The calculation of the expected mechanical loads under the influence of natural factors showed that all the considered options for $110 \mathrm{kV}$ high-voltage power line reconstruction satisfy the specified degrees of reliability. The article presents the developed methods for analyzing the functional reliability of the power system and proposes reliability indicators and a criterion for the efficiency of the operation of the $110 \mathrm{kV}$ OHTL that reflect the systemic effect of the implementation of measures for improving the reliability of such line. These indicators, in contrast to the existing ones, take into account the cumulative impact of natural and operational factors.
\end{abstract}

Keywords: Electrical systems; Failure; Overhead transmission lines; Power supply, Reliability; Wires

\section{Introduction}

One of the key issues of any electrical-energy system is reliable and uninterrupted power supply to the consumers. For the proper functioning of this system, reliable operation and appropriate technological conditions of all parts of the electric networks should be ensured (Budiyanto et al., 2011; Pariaman et al., 2017; Alvi et al., 2019; Alyunov et al., 2020; Dadabaev et al., 2020; Shevchenko et al., 2020). High-voltage power lines (HVLs) are used to deliver electricity over long distances, and their functioning strongly depends on the climatic conditions of the region (Budiyanto et al., 2011; Fedotov et al., 2016; Latipov et al., 2019). HVLs located in places with a sharply continental climate (i.e., extremely low temperatures in winter, extremely high temperatures in summer,

*Corresponding author's email: elena9racheva123@yandex.ru, Tel.: +79179186425 doi: 10.14716/ijtech.v11i8.4549 
high-speed wind, intense solar radiation, suspended particles of dust in the air) are subject to deteriorative influences. The damage of the $110 \mathrm{kV}$ high-voltage lines, which are important elements of HVLs, can significantly deteriorate the lines' reliability and can result in electricity undersupply. Several studies have been conducted to determine the reasons for HVL failure (Gracheva and Naumov, 2016; Gracheva and Naumov, 2019; Arief et al., 2018; Fomin et al., 2020). Weather factors (e.g., rain, snow, wind) are considered the main reasons for the decrease in reliability of 110 and $220 \mathrm{kV} \mathrm{HVLs.} \mathrm{As} \mathrm{electric} \mathrm{networks} \mathrm{are} \mathrm{large} \mathrm{systems}$ with multiple elements and multiple connections between them, a systematic approach should be used to study them. Ambient temperatures and wind cause material fatigue, which damages the constructions. Periodic kinks of wire are observed at the places of installation of the connecting and supporting clamps and vibration dampers, and cyclic lateral forces arise. The simultaneous impact of the above components leads to fatigue damage to the suspension systems. From the cyclic load, the nodes of the rigid structures that bear the maximum load are destroyed.

This paper presents the optimal option for $110 \mathrm{kV}$ overhead transmission line (OHTL) reconstruction in a sharply continental climate. The characteristics of the line (sag and tension) were calculated taking into account the weather conditions. On the basis of the calculated characteristics, we give recommendations herein on the possible reconstruction of the line that will ensure reliable operation under any natural load.

\section{Methods}

\subsection{Reliability Control Criteria}

The main criterion for the reliability of OHTLs is the permissible mechanical strength of such lines under the influence of various natural and operational factors (Toshkhodzhaeva and Khodzhiev, 2019). Reliability criterion $K_{\mathrm{n}}$ is proposed as a complex indicator that integrates the reliability of the OHTL elements during operation under the influence of the wind load, ambient temperature, current load, and the intensity of solar radiation. It can be calculated using the following formula:

$$
K_{n}=f\left(\sigma_{\text {wind }}, \sigma_{s . r}, \sigma_{I}, \sigma_{\text {temp }}\right) \leq \sigma_{\text {oth }}
$$

where $\sigma_{\text {wind }}$ is the mechanical load from the wind speed, $\sigma_{\text {s.r. }}$ is the mechanical load from solar radiation, $\sigma_{I}$ is the mechanical load from the current load, and $\sigma_{t e m p}$ is the mechanical load from the temperature.

The strength of the OHTL wire depends on operational safety factor $k_{e}$, which is determined using the following equation:

$$
k_{e}=\frac{\sigma_{p}-\sigma_{I}}{\sigma_{4}-\sigma_{I}}
$$

where $\sigma_{I}$ and $\sigma_{4}$ are the specific loads on the wire due to the gravity and when exposed to other loads $\left(\mathrm{N} / \mathrm{m}^{3}\right)$, and $\sigma_{p}$ is the specific breaking load of the wire $\left(\mathrm{N} / \mathrm{m}^{3}\right)$.

The specific breaking load of wire $\sigma_{p}$ is expressed as

$$
\sigma_{p}=\sigma_{n} \sqrt{24 \cdot\left(\frac{\varepsilon}{l^{2}}-\frac{\sigma_{o t h}}{E \cdot l^{2}}\right)+\frac{\sigma_{4}^{2}}{\sigma_{o t h}^{2}}}, N /\left(m \cdot m^{2}\right)
$$

where $\sigma_{n}$ is the stability limit of the conductor $\left(\mathrm{N} / \mathrm{mm}^{2}\right), \varepsilon$ is the relative elongation of the conductor, $l$ is the length of the span between the supports $(\mathrm{m}), \sigma_{\text {oth }}$ is the permissible voltage on the conductor $\left(\mathrm{N} / \mathrm{mm}^{2}\right)$, and $E$ is the modulus of elasticity of the conductor $\left(\mathrm{N} / \mathrm{mm}^{2}\right)$. 
It can be seen in Equation 3 that the actual breaking load and the operational safety factor of wires increase with a reduction in the span of the wires, and depend on the material used. A simple way to increase this indicator is to increase the design load while reducing the spans and the constant sag. Thus, efficiency and reliability are the main criteria to be considered. Reliability criterion $k_{n}$ is a complex indicator that combines design reliability and operation reliability. The mechanical reliability of a $110 \mathrm{kV}$ OHTL is a function of the following three parameters:

$$
k_{n}=f\left(q_{1}=P_{p r} ; q_{2}=P_{u s e} ; q_{3}=k_{e}^{1}\right)
$$

where $q_{1}=P_{p r}$ is a comprehensive indicator of design reliability, $q_{2}=P_{\text {use }}$ is a comprehensive indicator of operation reliability, and $q_{3}=P_{e}{ }^{1}$ is the operational safety factor.

It is advisable to express operation reliability by means of specific loads on the conductive material. This shows the multiplicity of the permissible load to the smallest one and is determined using the following formula (Toshkhodzhaeva and Khodzhiev, 2019):

$$
k_{e}^{1}=\frac{\gamma_{B}-\gamma_{1}}{\gamma_{4}-\gamma_{1}}
$$

where $\gamma_{4}$ and $\gamma_{1}$ are the specific loads on the wire when exposed to wind loads and from the mass of the conductive material $\left(\mathrm{N} / \mathrm{m}^{3}\right)$, and $\gamma_{\mathrm{w}}$ is the specific breaking load $\left(\mathrm{N} /\left(\mathrm{m} \cdot \mathrm{mm}^{2}\right)\right.$ ).

\subsection{Options for OHTL Reconstruction}

The analysis of the influences of the aforementioned factors on the $110 \mathrm{kV}$ OHTL operation in a sharply continental climate yielded three proposed options for their reconstruction. The reconstruction is aimed at mitigating the influence of natural factors, thus resulting in decreasing the number of accidents that may occur. When choosing a reconstruction option, one should take into account not only the separate influences of the wind pressure, the intensity of solar radiation, and the load on the conductor but also their integrated effects.

One of the most acceptable OHTL reconstruction options as it ensures high reliability is to build an OHTL on multifaceted metal supports (MMSs). Such OHTL reconstruction option has been applied in many states for 50-55 years. Supports are reliable elements of OHTLs, but their destruction has very serious consequences. It can lead to significant costs associated with support restoration and electricity supply shortage. In addition, the recovery time in such accidents is much longer than that in the case of destruction of other OHTL elements. According to some experts, damage to $110 \mathrm{kV}$ OHTLs associated with partial or complete damage of the MMSs is less often observed than damage to $110 \mathrm{kV}$ OHTLs with other types of support, especially in a sharply continental climate. Studies have shown that MMSs can withstand loads two to three times more than reinforced concrete supports can.

The high reliability of MMS can reduce the operating costs by $25-50 \%$ (Toshkhodzhaeva, 2017). It is more efficient to use MMS in mountainous conditions, however, because less area is required for land allotment. One of the best MMSs is that produced by Muromenergomash (Russian Federation).

Thus, considering the MMS characteristics, it can be concluded that the use of MMS while building an OHTL can:

- increase the reliability of the $110 \mathrm{kV}$ OHTL;

- reduce the cost of construction and installation work;

- shorten the construction time; and

- reduce the operating, transport, and annual costs. 
Reinforcement is one of the important elements of a $110 \mathrm{kV}$ OHTL, whose damage will lead to electricity supply shortage. Damage to the reinforcement from the applied load occurs due to material fatigue. The main reasons for damage to the reinforcement are the "dancing" of the wires and cables, vibration, etc. Under the action of wind force on this element, periodic bends of the wire are likely to be observed in the places of installation of the connecting and supporting clamps and vibration dampers, and cyclic transverse forces arise.

In Tajikistan, porcelain and glass insulators are mainly used on AC HVLs. Despite the positive characteristics of such insulators, they also have disadvantages, foremost of which is their relatively low mechanical strength. The mechanical strength of porcelain plate insulators is decreased by dielectric losses. For glass insulators, their mechanical strength decreases depending on the temperature difference and the possible damage to such insulators caused by external forces. The main advantage of the listed glass insulators is that tempered glass crumbles in case of defect, which greatly facilitates the identification of the damaged areas. In addition to plate-type insulators (suspended), porcelain insulators (rod) that work for shear or bend are also used. The latter insulators are widely used in Germany and Belgium for fixing the main wires, and in Russia they are used when tracing a loop on an anchor support. These insulators are manufactured taking into account a $157 \mathrm{kN}$ breaking load as they are well cleaned by wind and rain and are more profitable when operated in areas with a chemically active environment.

New types of insulators based on polymer materials have recently been developed. They have a number of advantages: low specific gravity (eight to ten times less than that of glass insulators), compactness, simple production technology, and hydrophobicity; consequently, they also have low contamination, long service life, resistance to natural factors, and minimal labor costs when used to replace the insulators of overhead power lines. Polymer insulators are recommended for use in foothill and mountainous areas with heavy pollution.

For example, in the Sughd region in Tajikistan, migratory birds are among the main reasons for the failure of $110 \mathrm{kV}$ OHTLs (i.e., up to $18 \%$ of the failure cases are due to migratory birds). Birds pollute the surfaces of insulators with their droppings. Even if such failure type is temporal, thousands of birds listed in the Red Book die every year. In addition, power supply organizations have incurred heavy losses. For this reason, the LKP$110 \mathrm{kV}$ bird-protection polymer insulator (Insta LLC, Russian Federation) was developed. The developed elongated shield retains the positive properties of the circular shield and allows rain to flush contaminants from the insulator unhindered. This insulator has several advantages, as follows:

- the screen prevents insulator contamination by droppings;

- the screen elongated along the wire protects overlap from the stream of bird droppings sitting on the traverse part above the insulator;

- the screen elongated along the wire prevents a short circuit when the bird sitting next to it cleans its beak; and

- the screen narrowed across the wire does not interfere with the natural cleaning of the insulation by rain.

It was found that up to $65 \%$ of the failures of $110 \mathrm{kV}$ OHTLs are wire failures. As such, when developing reconstruction options, special attention is paid to them. Today, the following are required for conductive wire materials:

- the highest electrical conductivity;

- the greatest mechanical strength;

- the smallest linear mass; 
- $\quad$ stability at the maximum temperature;

- the lowest elongation temperature; and

- resistance to wear and wind pressure.

Wires and lightning-protection cables must have mechanical strength and low electrical resistivity, must be able to withstand atmospheric influences, and must have sufficient elongation at break. In Tajikistan, AC steel-aluminum wires are mainly used. The sag arrows for such wires are much smaller than those for aluminum and steel wires while the mechanical characteristics are much higher.

Current load and ambient temperature have an impact on sag arrows and wire voltage. Increasing ambient temperature results in increased sag and decreased wire voltage, and the opposite situation takes place with decreasing temperature. During modeling, it is advisable to consider the following temperatures (Rakhimov et al., 2017; Toshkhodzhaeva and Khodzhiev, 2019):

- the highest temperature resulting in the longest wire extension and the highest sag;

- the lowest temperature resulting in the shortest wire and the lowest voltage; and

- the average annual temperature that meets the operating conditions.

\subsection{Analysis of the Impact of Natural and Climatic Loads on OHTL}

To analyze the impact of natural and climatic loads on the $110 \mathrm{kV}$ high-voltage OHTL, it is necessary to determine the initial parameters of the line, which show the state of the high-voltage cable under normal operating conditions. In a sharply continental climate, the state of high-voltage OHTLs in the absence of wind and $\mathrm{a}+25^{\circ} \mathrm{C}$ conductor material temperature are accepted.

When determining the initial mechanical loads, the total tension $T t$ is calculated, which consists of vertical component $V t$ and horizontal component $H \mathrm{t}$. The sag for all the selected wire variation $f t$ is calculated using the following equation:

$$
f_{t}=\frac{\gamma_{1} \cdot\left(l_{c a l}\right)^{2}}{8 \cdot \sigma_{t}}
$$

where $\gamma_{1}$ is the specific load from the wires' own weight $\left(\mathrm{N} /\left(\mathrm{m} \cdot \mathrm{mm}^{2}\right)\right), l_{\text {cal }}$ is the calculated wire length (m); and $\sigma t$ is the force per unit of the wire section $\left(\mathrm{N} / \mathrm{mm}^{2}\right)$.

The mechanical stress in conductor $\sigma_{t}$ is determined using the equation of state (Athas et al., 1994; Amin and Stringer, 2008):

$$
\sigma_{t}-\frac{\gamma_{1}^{2} \cdot\left(l_{c a l}\right)^{2} \cdot E}{24\left(\sigma_{t}\right)^{2}}=\sigma_{p e r}-\frac{\gamma_{1}^{2} \cdot\left(l_{c a l}\right)^{2} \cdot E}{24\left(\sigma_{p e r}\right)^{2}}-\alpha_{l . r} \cdot E \cdot\left(t-t_{n}\right)
$$

where $t$ is the ambient temperature $\left({ }^{\circ} \mathrm{C}\right), t=-20^{\circ} \mathrm{C}$ the minimum temperature, $E$ is the conductor elastic modulus $\left(\mathrm{N} / \mathrm{mm}^{2}\right), \alpha$ l.r is the temperature coefficient of linear expansion of the wire, $\sigma_{p e r}$ is the permissible force per unit of the wire section $\left(\mathrm{N} / \mathrm{mm}^{2}\right), t$ is the ambient temperature $\left({ }^{\circ} \mathrm{C}\right)$; and $t_{n}$ is the measured temperature $\left({ }^{\circ} \mathrm{C}\right)$.

The horizontal component of the conductor full tension $\left(\mathrm{H}_{\mathrm{t}}\right)$ (Barker and De Mello, 2000; Benini et al., 2000; Amin and Stringer, 2008) is determined using the following equation:

$$
H_{t}=\frac{M_{0} \cdot 10^{-3} \cdot\left(l_{c a l}\right)^{2}}{8 \cdot f_{t}}
$$

The vertical component of the conductor full tension $\left(V_{t}\right)$ is determined using the equation below.

$$
V_{t}=M_{0} \cdot 10^{-3} \cdot l_{c a l}
$$


Full wire tension $T_{t}$ is calculated using the equation below.

\subsection{Wire Options}

$$
T_{t}=\sqrt{\left(H_{t}\right)^{2}+\left(V_{t}\right)^{2}}
$$

In addition to mechanical and natural loads, current loads also affect the OHTL wire during its operation. Thus, three wire options were considered based on their composite materials. Such wires are extensively used worldwide to increase the reliability of the 110 kV OHTLs.

Option I. Composite high-temperature GTACSR wire from J-Power Systems, Japan. The working temperature of the wire is $150^{\circ} \mathrm{C}$, and the super-heat-resistant alloy ZTAL is used in the current-conducting part. As a result, due to the increased temperature, the elongation coefficient of the wire material becomes lower for the conductor than for steel-aluminum. Accordingly, the sag arrow also decreases.

Option II. TACSR series wires from Lumpi-Berndorf, Austria. Increased conductivity of the conductor is achieved due to the high operating temperature. These wires, compared with the traditional ones, are highly heat-resistant. In the natural environment, they are able to withstand significant current loads for a long time. Their structure is identical to that of the conductors of the AC brand. The use of heat-resistant aluminum significantly increases the wire's heat resistance. The electrical conductivity of the TACSR wire is 1.5 times more than that of the AC wire, but the TACSR wire has a smaller diameter. This makes it possible to lengthen the distance between the supports and to reduce the load on the line. Structurally, these wires are identical to the traditional ones, and they do not require additional costs for installation work.

Option III. ACCR (aluminum conductor composite reinforced) wire based on a composite material from the American company $Z M$. This wire has the ability to pass two to three times more current volume compared to the traditional conductors of the same cross-section without losing its mechanical properties (Beryozkina, 2019). In addition to its high conductivity, the ACCR wire is lighter, has high strength and resistance to high temperatures compared with the existing analogues, is less susceptible to corrosion, and has high fatigue resistance. It also does not harm the environment (does not cause environmental degradation). The wire is currently being used successfully in many countries around the world. Since 2007, a new-generation ACCR wire has been used in Russia.

ACCR is a stranded conductor composed of a steel core and live conductors. The composite core consists of several wires with 1.9-2.9 mm diameters, which are made of high-purity aluminum. They are more than 25,000 micrometers in diameter and are continuous along the entire length of the longitudinal fibers of aluminum oxide $\left(\mathrm{Al}_{2} \mathrm{O}_{3}\right)$. Thus, each wire of the core is a matrix. Alumina fibers give ultra-high strength to the material. In appearance, the composite core is similar to that of a standard aluminum wire, but its physical and mechanical characteristics differ from those of both aluminum and steel analogues, as follows:

- the strength characteristics of the composite core are comparable to those of the steel core and are eight times more than those of aluminum;

- the composite core is two times lighter than the steel core, and its mass is $20 \%$ more than that of pure $\mathrm{Al}$;

- the electrical conductivity of the ACCR core is four times higher than that of steel;

- the coefficient of thermal expansion of ACCR core is two times less than that of steel and four times less than that of aluminum; and

- the ACCR core is three times more rigid than that of aluminum core. 
The surface conductors of the ACCR wire are made of heat-resistant Al-Zr alloy. This alloy has the strength of the standard aluminum, but the addition of zirconium enables it to retain its strength at higher temperatures. According to the rules for the arrangement of electrical installation, ordinary aluminum can be used in continuous operation at temperatures up to $70^{\circ} \mathrm{C}$, and as has been shown by numerous studies, up to $90^{\circ} \mathrm{C}$ without sacrificing the strength. At a $120-150^{\circ} \mathrm{C}$ temperature, aluminum "anneals" and irreversibly loses its strength. This is very important because the annealed aluminum of the outer layer of the AC wire is not capable of further bearing the mechanical load; only the steel core "remains in the game." Under certain external conditions, such as at $-40^{\circ} \mathrm{C}$ and below, it can even completely collapse. The Al-Zr alloy of the ACCR wire retains its properties up to $210^{\circ} \mathrm{C}$ in continuous operation, and short-term peak loads up to $240^{\circ} \mathrm{C}$ are allowed.

The main cases of application of the high-temperature ACCR composite wire and when and where it is advisable to use its unique properties were considered. To compare the selected wire types, the traditional AC brand wire was used as a basis. The comparative characteristics of the traditional AC wires and the high-temperature wires are shown in Table 1.

Table 1 Comparative characteristics of traditional AC wires and high-temperature wires

\begin{tabular}{llccccccc}
\hline Manufacturer & Brand & $\begin{array}{c}F_{\text {tr }} / F_{\mathrm{c}}, \\
\mathrm{mm}^{2} / \mathrm{mm}^{2}\end{array}$ & $\begin{array}{c}T_{\text {per, }} \\
{ }^{\circ} \mathrm{C}\end{array}$ & $\begin{array}{c}D_{\text {pr, }} \\
\mathrm{mm}\end{array}$ & $\begin{array}{c}M_{\text {pr.0, }} \\
\mathrm{kg} / \mathrm{km}\end{array}$ & $\begin{array}{c}I_{\text {per, }} \\
\mathrm{A} / \mathrm{p} . \mathrm{u} .\end{array}$ & $\begin{array}{c}C_{0}, \\
\text { p.u. }\end{array}$ & $f_{\text {pr, }} \mathrm{m}$ \\
\hline $\begin{array}{l}\text { Russian } \\
\text { factories }\end{array}$ & AC & $240 / 39$ & 90 & 21.6 & 952 & $480 / 1.0$ & 1.0 & 10.1 \\
L-B & TACSR/ACS & $212 / 49$ & 150 & 21.0 & 914 & $870 / 1.8$ & 3.6 & 11.6 \\
JPS & GTACSR & $217 / 49$ & 150 & 20.3 & 1015 & $840 / 1.7$ & 6.0 & 12.1 \\
3M & ACCR & $238 / 39$ & 210 & 21.6 & 793 & $1210 / 2.5$ & 13.0 & 12.9 \\
\hline
\end{tabular}

Replacing the commonly used wires with heat-resistant ones with a small sag makes it possible to increase the long-term permissible current of the wire under the same operating conditions. Long-term operation at temperatures up to $200^{\circ} \mathrm{C}$ without changing the mechanical and electrophysical properties makes it possible to reduce the electrical resistance of wires by about $40 \%$. Thus, an algorithm and a method for choosing the optimal type of construction for a $110 \mathrm{kV}$ OHTL with a given degree of reliability in a sharply continental climate were developed. A distinctive feature of the developed method is that it can be implemented through a computer, which can be used to solve the problems concerning the design and operation of the power system.

\section{Results and Discussion}

A special program was developed in the Matlab/Simulink program to perform calculations using the above formulas (Lakervi and Holmes, 1995; Gregorio et al., 1997; Henkel, 1999; Kiessling et al., 2003). Such program allowed us to calculate Hu, the horizontal components of wire tension $(\mathrm{N} / \mathrm{m})$; $\mathrm{Vv}$, the vertical component of wire tension; $\mathrm{Tu}$, the full component of wire tension; and sag arrows $f$ as a function of temperature. The considered ambient temperatures were in the range of -25 to $40^{\circ} \mathrm{C}$, and the wind speed was considered constant at $\vartheta=10 \mathrm{~m} / \mathrm{s}$ (Matsuoka et al., 1996; Amin and Stringer, 2008; Billinton and Li, 2013). Figures 1 and 2 present the relationship between wire voltage and sag and ambient temperature. 


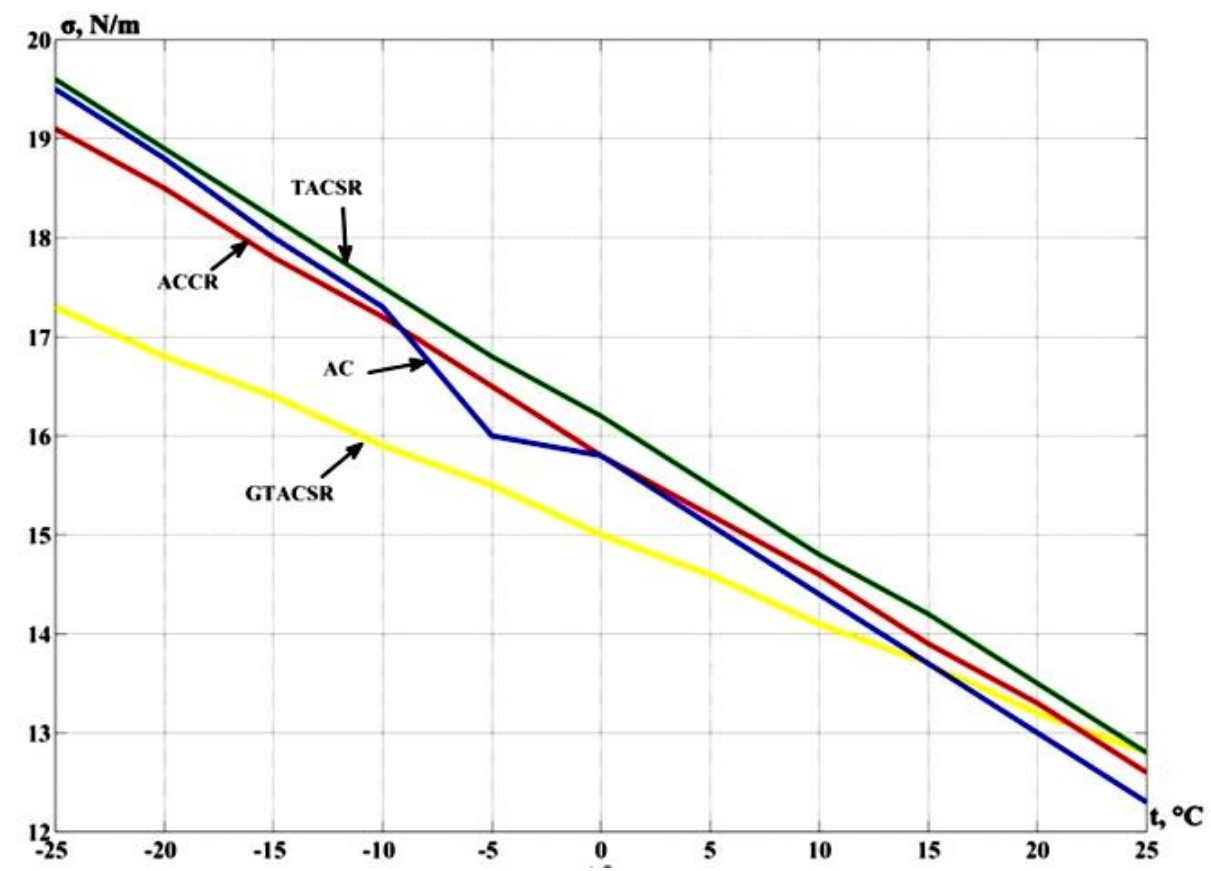

Figure 1 Relationship between wire voltage and ambient temperature

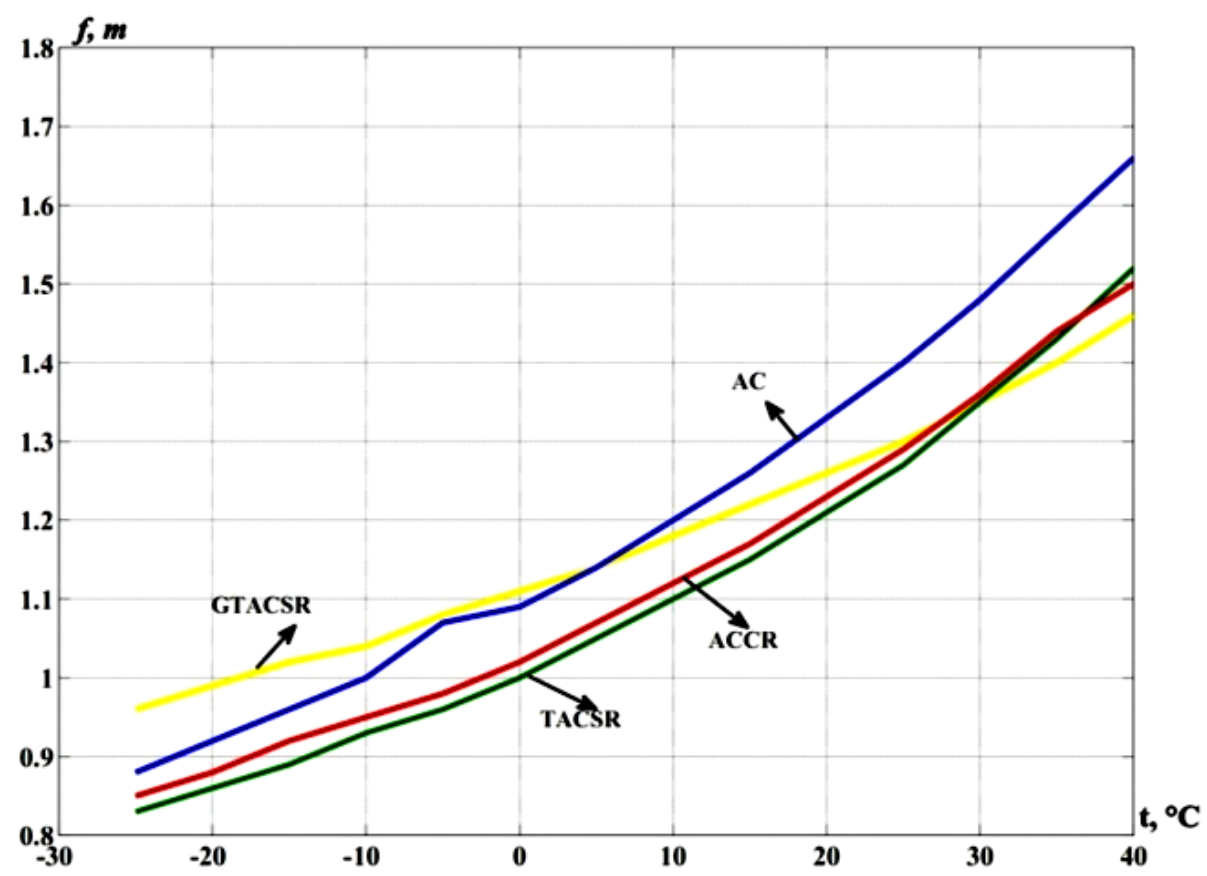

Figure 2 Relationship between wire sag and ambient temperature

With increasing temperature, the wire voltage linearly decreased while the wire sag increased. The wire voltages were practically the same for the maximum considered temperature of $25^{\circ} \mathrm{C}$ while the wire tensions were the same at the minimum considered temperature. However, the various wire types showed a different behavior with temperature change. For the considered temperature range, the average voltage decreased 1.58 times. The $+15^{\circ} \mathrm{C}$ temperature (at which the curves crossed the permissible voltage) was typical for all the wires. The tension on the TACSR and ACCR wires was 1.4 times higher than the acceptable values at the minimum temperatures and 1.3 times less than the acceptable values at the maximum temperatures. A distinctive feature of high-temperature 
wires is that at the maximum temperatures, they have higher tension than the traditional ones; therefore, the sag will be less than that of the AC wire. Figure 2 compares the sag at the maximum temperature for all the wire types to the sag at the maximum temperature for the AC wire. It should be noted that at the maximum temperatures the sag of all the wires was significantly less than the critical value. A more detailed discussion is presented in Schlichting (1978), Barbur et al. (1994), Reddy (2011), and Khasanov et al. (2020).

The relationship between wire tension and ambient temperature is presented in Figure 3 (Khasanov et al., 2020). It is shown in the said figure that this relationship is mainly governed by the mechanical properties of the conductive materials.

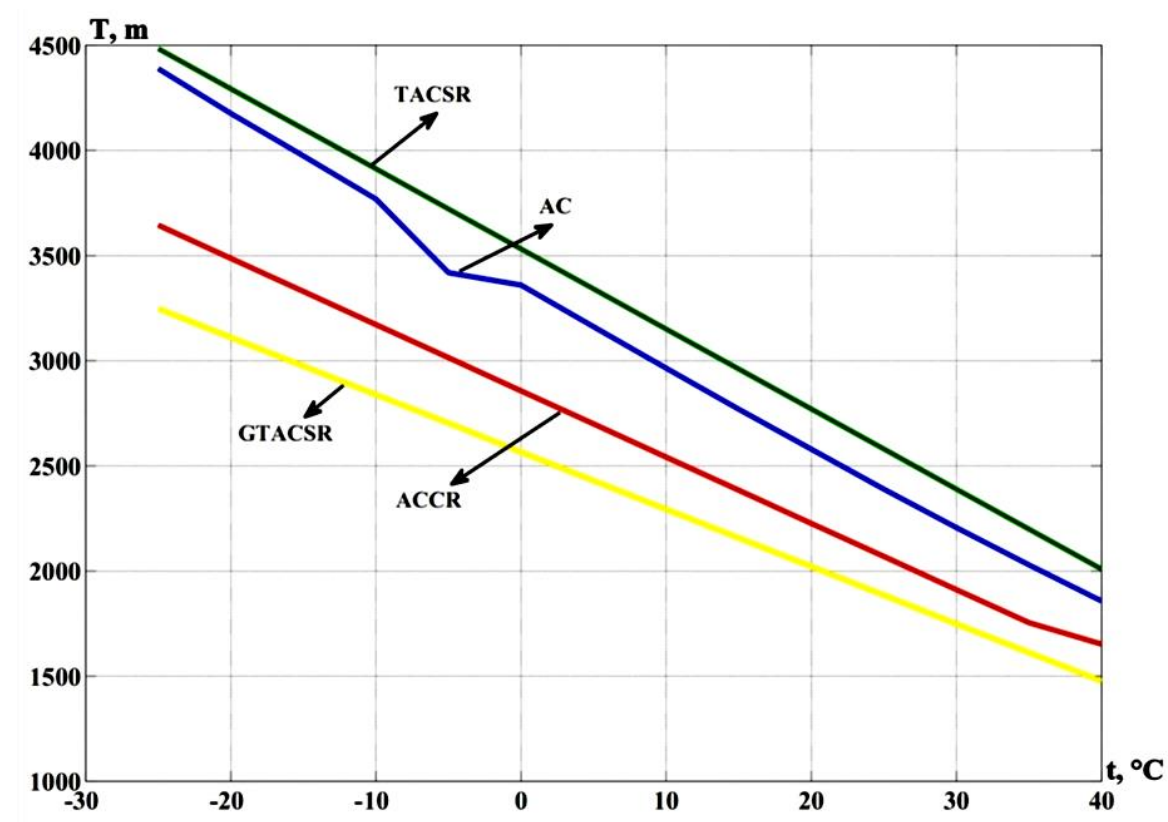

Figure 3 Relationship between wire tension and ambient temperature

The coefficient of non-uniformity was calculated depending on wind speed $\alpha$, the standard high-speed wind pressure at a height of $10 \mathrm{~m}$ from the earth's surface. The qn downwind region and the coefficient of increase of the high-speed wind pressure in height were also taken into account.

Sag arrows f $\vartheta$ were determined using the equation below.

$$
f_{\vartheta}=\frac{\gamma_{4} \cdot\left(l_{c a l}\right)}{8 \cdot \sigma_{\vartheta}}
$$

The specific load on wire $\gamma 4$ was calculated using the equation below (Rakhimov et al., 2017; Khasanov et al., 2020).

$$
\gamma_{4}=\sqrt{\gamma_{1}^{2}}+\left(\frac{\alpha \cdot C_{x} \cdot \vartheta^{2} \cdot d_{n}}{1.6 \cdot 10^{-3} \cdot F}\right)^{2}
$$

The voltage in wire was calculated using the equation below.

$$
\sigma_{v}-\frac{\gamma_{6}^{2} \times\left(l_{c a l}\right)^{2} \times E}{24 \times\left(\sigma_{v}\right)^{2}}=\sigma_{d o p}--\frac{\gamma_{1}^{2} \times\left(l_{c a l}\right)^{2} \times E}{24 \times\left(\sigma_{d o p}\right)^{2}}-\alpha_{l . r .} \times E \times\left(t_{g}-t_{n}\right)
$$

The horizontal components $\mathrm{Hu}$ of the full tension of the wire were determined using the equations below. 


$$
\begin{gathered}
H_{v}=\frac{\sqrt{\left(M_{0} \cdot 10^{-3}\right)^{2}+\left(P_{v}\right)^{2}} \cdot\left(l_{c a l}\right)^{2}}{8 \cdot f_{v}} \\
P_{v}=6,25 \cdot 10^{-5} \cdot \alpha \cdot C_{x} \cdot v^{2} \cdot d_{n} .
\end{gathered}
$$

The vertical components $\mathrm{Vu}$ of the full tensile wire were calculated using the following equation:

$$
\mathrm{V}_{v}=\sqrt{\left(M_{0} \cdot 10^{-3} \cdot l_{c a l}\right)^{2}+\left(P_{v} \cdot l_{c a l}\right)^{2}} .
$$

Full conductor tension Tu was obtained using the equation below.

$$
T_{v}=\sqrt{\left(H_{v}\right)^{2}+\left(V_{v}\right)^{2}}
$$

Equations 14-17 were used to calculate tensions $\mathrm{Hv}, \mathrm{Vv}$, and $\mathrm{Tv}$ occurring in the conductors without ice. Changing wind speeds of $v=0,10,20$, and $30 \mathrm{~m} / \mathrm{s}$ and ambient temperature $\operatorname{tg}=+10^{\circ} \mathrm{C}$ were considered. Figure 4 shows the relationship between wire sag and wind speed.

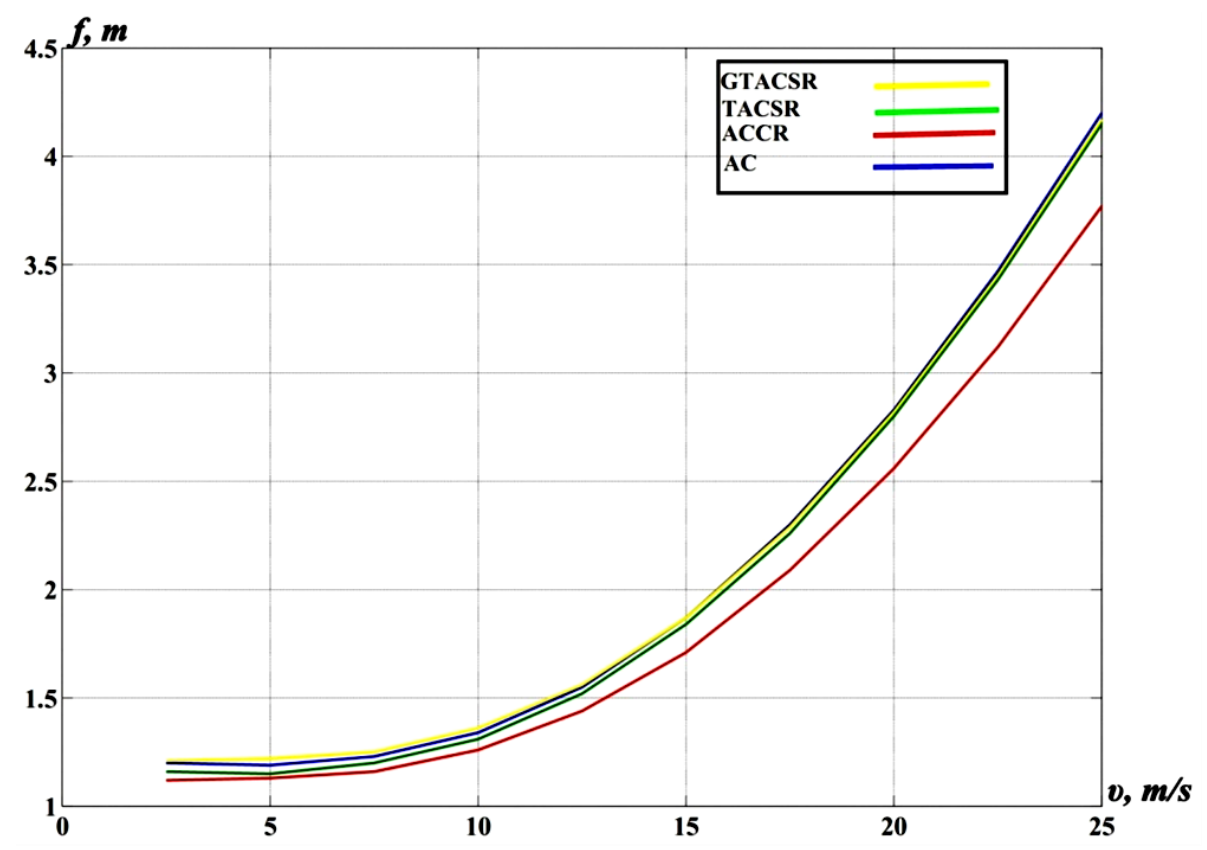

Figure 4 Relationship between wire sag and wind speed

The GTACSR, TACSR, and AC wires showed similar sag behaviors as a function of wind speed. For the ACCR wire at the maximum wind speed, the change in the sag was $11 \%$ less than that for the AC wires. At the highest wind speed, the change in the sag arrow was less than permissible. This was due to the fact that in sharply continental climates there is practically no ice formation on the wires. The relationship between wire tension and wind speed is presented in Figure 5.

The calculations and data presented in Figure 5 allow us to conclude that wind pressure does not have a strong impact on wires if they are not covered by ice. Thus, even at a wind speed of $25 \mathrm{~m} / \mathrm{s}$, the tension on the wires did not exceed the critical value, and the overall dimensions of the lines were within the acceptable limits.

To improve the reliability of $110 \mathrm{kV}$ OHTLs, reliability criteria were developed taking into account the influence of natural factors, which are complex indicators of reliability at 
the design and operation stages and take into account the physical and mechanical strength of wires.

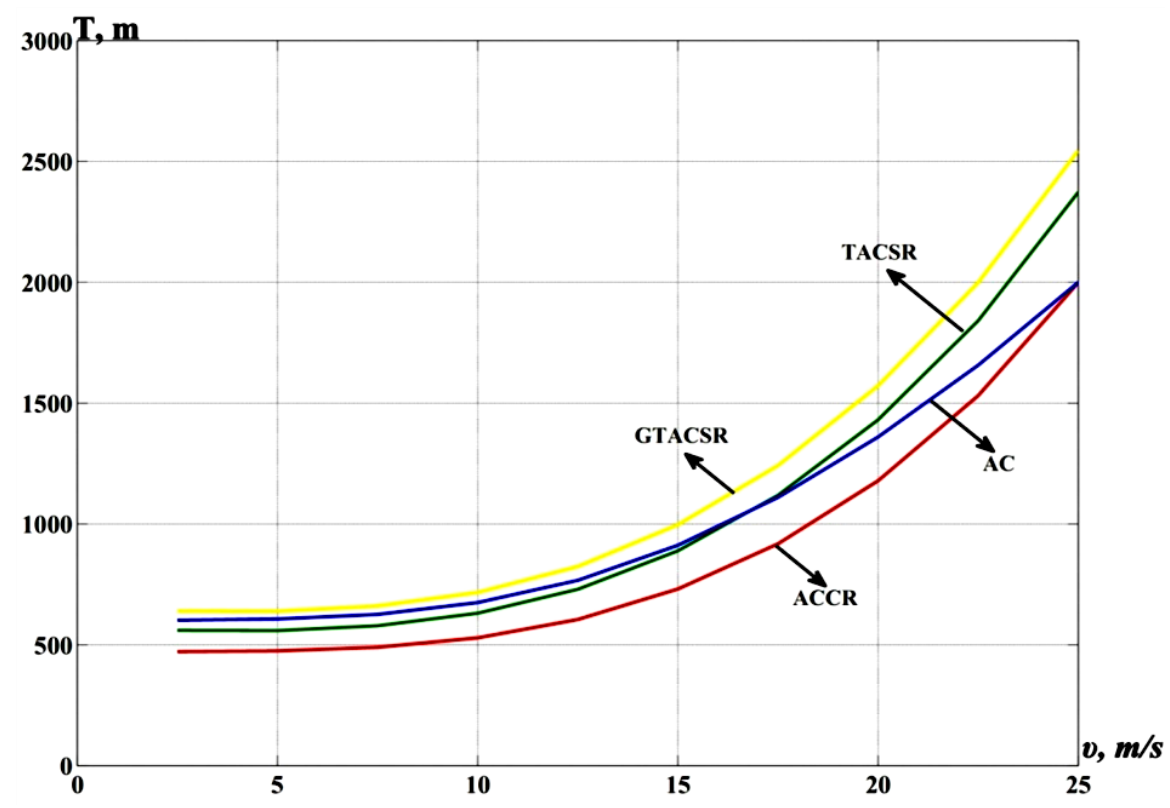

Figure 5 Relationship between wire tension and wind speed

A complex indicator that takes into account the reliability of the elements of a $110 \mathrm{kV}$ OHTL during operation under the influence of ambient temperature, intensity of solar radiation, wind pressure, and current loads is proposed as a criterion. On the basis of the results of the comparison of the physical and mechanical properties of high-temperature composite wires, an optimal variant of reconstruction of a $110 \mathrm{kV}$ OHTL with an increased level of reliability was developed.

\section{Conclusions}

When developing an optimization model for OHTLs, it is necessary to take into account operational and natural factors. In the study reported in this paper, mathematical modeling was performed using the specially developed Matlab/Simulink software. The most common types of wires for OHTL were considered. The results of the study showed that when the relief, climate, and operational factors change, the level of reliability is $95 \%$. It was shown that the TACSR wire has the greatest reliability at the maximum temperatures; as such, its sag at the maximum temperatures was the smallest. Therefore, from the point of view of the influence of temperature on ensuring the HVL reliability, the TACSR wire is optimal. The calculation of the expected mechanical loads under the influence of natural factors showed that all the considered options for the reconstruction of the $110 \mathrm{kV}$ HVLs satisfy the specified degrees of reliability.

\section{References}

Alvi, M.J., Izhar, T., Qaiser, A.A., Anjum, A., Ul Hassan, R., 2019. Electro-mechanical Design and Creep Analysis of Proposed Enclosure for Flexible Gas Insulated Line Regarding Subsurface Metropolitan Applications of High-voltage Transmission Lines. Electronics (Switzerland), Volume 8(9), p. 929

Alyunov, A.N., Vyatkina, O.S., Udaratin, A.V., Zaripova, D.A., 2020. Technical and Economic Efficiency of Proactive Diagnostic Systems for Power Transformers. E3S Web of 
Conferences, Volume 178, p. 01081

Amin, M., Stringer, J., 2008. The Electric Power Grid: Today and Tomorrow. MRS Bulletin, Volume 33(4), pp. 399-407

Arief, A., Nappu, M.B., Antamil, 2018. Analytical Method for Reactive Power Compensators Allocation. International Journal of Technology, Volume 9(3), pp. 602-612

Athas, W.C., Svensson, J., Koller, J.G., Tzartzanis, N., Chou, Y.C., 1994. Low-Power Digital Systems based on Adiabatic-Switching Principles. IEEE Transactions on Very Large Scale Integration (VLSI) Systems, Volume 2(4), pp. 398-407

Barbur, V.A., Montgomery, D.C., Peck, E.A., 1994. Introduction to Linear Regression Analysis. The Statistician, Volume 43(2), p. 339

Barker, P.P., De Mello, R.W., 2000. Determining the Impact of Distributed Generation on Power Systems: Part 1 - Radial Distribution Systems. In: Proceedings of the IEEE Power Engineering Society Transmission and Distribution Conference, Volume 3, pp. 16451656

Benini, L., Bogliolo, A., De Micheli, G., 2000. A Survey of Design Techniques for System-Level Dynamic Power Management. IEEE Transactions on Very Large Scale Integration (VLSI) Systems, Volume 8(3), 299-316

Beryozkina, S., 2019. Evaluation Study of Potential use of Advanced Conductors in Transmission Line Projects. Energies, Volume 12(5), p. 822

Billinton, R., Li, W., 2013. Reliability Assessment of Electric Power Systems using Monte Carlo Methods. Springer Link

Budiyanto, B., Setiabudy, R., Setiawan, E.A., Sudibyo, U.B., 2011. Development of Direct Current Microgrid Control for Ensuring Power Supply from Renewable Energy Sources. International Journal of Technology, Volume 2(3), pp. 199-206

Dadabaev, S.T., Islomovna, T.M., Saidulloevna, M.D., 2020. Modeling of Starting Transition Processes of Asynchronous Motors with Reduced Voltage of the Supply Network. European Journal of Electrical Engineering, Volume 22(1), pp. 23-28

Fedotov, A.I., Gracheva, E.I., Fedotov, E.A., Chernova, N.V., 2016. Local Fourier Transformation Application for Mathematic Modeling of Synchronous Machine Valve Actuator. Journal of Engineering and Applied Sciences, Volume 11(13), pp. 2939-2945

Fomin, I.N., Belikov, R.P., Kudinova, T.A., Tsvetkov, A.N., 2020. Identification Power Line Sections with Increased-Electricity Losses using Sensors with Wi-Fi Technology for Data Transmission. E3S Web of Conferences, Volume 178, p. 01083

Gracheva, E.I., Naumov, O.V., 2019. Estimation of Power Losses in Electric Devices of the Electrotechnical Complex. In: International Conference on Industrial Engineering, Applications and Manufacturing, ICIEAM 2019, p. 6

Gracheva, E.I., Naumov, O.V., 2016. Operating Mode Influence on Probability Characteristics of Electric Devices. Journal of Engineering and Applied Sciences, Volume 11(13), pp. 2934-2938

Gregorio, P., Ahmadi, M., Buehler, M., 1997. Design, Control, and Energetics of an Electrically Actuated Legged Robot. IEEE Transactions on Systems, Man, and Cybernetics, Part B: Cybernetics, Volume 27(4), pp. 626-634

Henkel, J., 1999. A Low Power Hardware/Software Partitioning Approach for Core-based Embedded Systems. In: Proceedings - Design Automation Conference, pp. 122-127

Khasanov, S.R., Gracheva, E.I., Toshkhodzhaeva, M.I., Dadabaev, S.T., Mirkhalikova, D.S., 2020. Reliability Modeling of High-voltage Power Lines in a Sharply Continental Climate. E3S Web of Conferences, Volume 178, p. 01051

Kiessling, F., Nefzger, P., Nolasco, J.F., Kaintzyk, U., 2003. Overhead Power Lines: Planning, Design, Construction. Springer-Verlag Berlin Heidelberg 
Lakervi, E., Holmes, E.J., 1995. Electricity Distribution Network Design. IET Digital Library, Volume 21, pp. 130-142

Latipov, S.T., Aslanova, G.N., Nematov, L.A., Akhmedov, A.A., Charieva, M.R., 2019. Calculation of Reliability Indicators of Power Supply Systems of Consumers. E3S Web of Conferences, Volume 139, p. 01037

Matsuoka, R., Shinokubo, H., Kondo, K., Mizuno, Y., Naito, K., Fujimura, T., Terada, T., 1996. Assessment of Basic Contamination Withstand Voltage Characteristics of Polymer Insulators. IEEE Transactions on Power Delivery, Volume 11(4), pp. 1895-1900

Pariaman, H., Garniwa, I., Surjandari, I., Sugiarto, B., 2017. Availability Analysis of the Integrated Maintenance Technique based on Reliability, Risk, and Condition in Power Plants. International Journal of Technology, Volume 8(3), pp. 497-507

Rakhimov, O.S., Khodzhiev, A.A., Toshkhodzhaeva, M.I., 2017. Improving the Reliability of $110 \mathrm{kV}$ High-voltage Power Lines at the Design and Operation Stages. Elektrooborudovanie: Ekspluatatsiya i Remont, Volume 3, pp. 55-57

Reddy, T.A., 2011. Applied Data Analysis and Modeling for Energy Engineers and Scientists. Boston: Springer, MA

Schlichting, J., 1978. Molybdenum Disilicide as a Component of Modern High-Temperature Composites. High Temperatures - High Pressures, Volume 10(23), pp. 241-269

Shevchenko, N., Soshinov, A., Elfimova, O., Lebedeva, J., Akhmedova, O., 2020. Improving the Energy Efficiency of Wide Crossings of Overhead Power Lines. E3S Web of Conferences, Volume 178, p. 01046

Toshkhodzhaeva, M.I., 2017. Comparative Analysis of the Mechanical Properties of Traditional and High-Temperature vlep Wires - $110 \mathrm{kV}$. Izvestiya Tul'skogo Gosudarstvennogo Universiteta. Tekhnicheskie Nauki, Volume 3, pp. 169-175

Toshkhodzhaeva, M.I., Khodzhiev, A.A., 2019. Features of Diagnosing High-voltage Power Lines of $110 \mathrm{kV}$ in a Sharply Continental Climate. Izvestiya Tul'skogo Gosudarstvennogo Universiteta. Tekhnicheskie Nauki, Volume 2, pp. 364-369 